\title{
1. Rumsliga uttryck för befintlighet och riktning
}

Hur man uttrycker befintlighet och riktning i svenska och i nederländska uppvisar ett komplext mönster som på ytan förefaller ha många likheter. I det här avsnittet diskuteras hur kombinationen verb och adverb kan uttrycka befintlighet eller riktning: gå hem 'naar huis gaan', vara ute 'buiten zijn', komma hit 'hier komen' och så vidare. I avsnittet behandlas främst verb som uttrycker konkret, fysisk rörelse och det mönster som presenteras gäller i stor utsträckning även när verben används i abstrakt betydelse, se (I.I) och (I.2). ${ }^{\mathrm{I}}$ Detta avsnitt gör dock inte anspråk på att ge en komplett bild av hela systemet med uttryck för riktning och befintlighet.

(I.I) Hon kom inte fram till något beslut. (abstrakt betydelse)

(I.2) Hon kom inte fram till flygplatsen i tid. (konkret betydelse)

Boken Svensk grammatik på svenska (I986, 2009) uppmärksammar befintlighets- och riktningsuttryck och de beskrivs där även i jämförelse med andra språk. ${ }^{2}$ Boken, som riktar sig till andraspråksinlärare av svenska, tar bl.a. upp här/där/var respektive hit/ dit/vart och befintlighetadverbialen hemma, borta, inne, ute, uppe, nere, framme respektive riktningsadverbialen hem, bort, in, upp, ner, fram. Svenskan har en morfologisk markering där hemma, borta, inne, ute, uppe, nere, framme markerar befintlighet medan hem, bort, in, ut, upp, ner, fram markerar riktning. Denna språkstruktur behandlas i andra- och tredjespråksundervisningen just p.g.a. att den morfologiska distinktionen mellan befintlighet och

Hur du refererar till det här kapitlet:

Johansson, A. 2019. Kontrastiva studier i nederländska och svenska: Med en inledning om tredjespråksinlärning och tvärspråklig medvetenhet. Pp. I527. Stockholm: Stockholm University Press. DOI: https://doi.org/Io.I6993/ baz.b License: CC-BY. 
riktning i svenskan uppfattas som en svårighet vid inlärningen av svenska. Svensk grammatik på svenska har för avsikt att behandla grammatik som är språkspecifik för svenska. Liknande morfologisk markering återfinns inte i till exempel nederländskan, engelskan eller tyskan trots att dessa är närbesläktade språk till svenskan. Vad gäller nederländska uttrycks istället riktning respektive befintlighet med en annan struktur. I nederländskan anger hier 'här', daar 'där', waar 'var', thuis 'hemma', binnen 'inne', buiten 'ute', beneden 'nere' m.fl. befintlighet. Dessa har ingen morfologisk markering som i svenska för att uttrycka riktning. I följande avsnitt diskuteras denna struktur för båda språken med avstamp i svenskan.

\section{Befintlighets- och riktningsuttryck i svenska}

Ovanstående befintlighets- respektive riktningsuttryck kombineras med olika verb där adverbet styr kombinationens betydelse men i vissa fall får även verbets semantik genomslag. Statiska verb såsom vara, stå, sova m.fl. kombineras bara med befintlighetsuttryck eftersom riktning signalerar någon form av dynamik eller rörelse som inte motsvarar verbens semantik. Man kan säga att dessa verb även uttrycker befintlighet, jfr (I.3) och (I.4).

(I.3) Jag är hemma. - *Jag är hem

(I.4) Jag sitter inne och läser. - *Jag sitter in och läser

Verben komma, bege sig och ta sig kombineras övervägande med riktningsuttryck. Här förefaller just verbens betydelse av rörelse implicera ett mål för rörelsen. Av den anledningen blir en kombination med befintlighetsuttryck ogrammatisk eftersom dessa uttryck innebär ett skeende på en och samma plats så som i (I.5), (I.6) och (I.7).

(I.5) Hon kommer fram. - "Hon kommer framme

(г.6) Hon begav sig dit. - "Hon begav sig där

(I.7) Hon tar sig hem. - *Hon tar sig hemma

Rörelseverb - som inte har en inherent målbetydelse som hos ovan nämnda verb - kan kombineras både med befintlighets- och riktningsuttryck, till exempel gåa åka, springa, vandra. I dessa 
kombinationer är det adverbet som avgör om rörelsen sker på en och samma plats eller om det är en rörelse som har målfokus.

(г.8) Barnet sprang hit direkt. - Barnet sprang runt här.

(г.9) Går du ut? - Går du ute?

I (I.8) och (I.9) är adverben direkt och runt medskapande i satsens betydelse men skillnaden på hit/här respektive ut/ute talar sitt tydliga språk. Vidare ser man att den här typen av uttryck får en viss struktur om de kombineras med rums- eller tidsadverbial.

(I.Io) De går hemma i sin trädgård. - De går hem till sin trädgård.

(I.II) De springer här på hösten. - De springer hit på hösten.

(I.I 2) De vandrar borta på ängen. - De vandrar bort över ängen.

Om man tittar lite närmare på satserna i (I.IO), (I.II) och (I.I 2) urskiljer man ett mönster där uttrycken som är morfologiskt markerade för befintlighet hemma, här och borta också kombineras med prepositioner som anger befintlighet $i$ (sin trädgård) och $p a$ (ängen). Det motsatta gäller för uttrycken med hem och bort som markerar riktning i (I.IO) och (I.I I). Dessa kombineras däremot med riktningsprepositionerna till och över. I kontexter med ett statiskt verb kan över dock ange befintlighet som i tavlan hängde över sängen. Däremot fungerar både riktnings- och befintlighetsuttryck i kombination med tidsadverbial som inleds med prepositionen $p a ̊$ och $i$ som i (I.II) de springer här/hit på hösten. Tidsadverbialet på hösten anger en återkommande händelse, dvs. satsen är iterativ. Ett tidsadverbial med prepositionen $i$ är också ett exempel på när satsen kan kombineras både med riktnings- respektive befintlighetsuttryck: i vintras gick vi hit/här. Både hit/här är grammatiskt korrekt men anger olika betydelser.

En kombination med ett befintlighetsadverb och riktningsprepositioner fungerar sällan, jfr (I.I3), (I.I4) och (I.I 5).

(I.I3) *Vi går borta till grannen (Vi går bort till grannen)

(I.I4) "Vi vandrar hemma genom parken (Vi vandrar hem genom parken)

(I.I 5) *Vi springer nere till vägen (Vi springer ner till vägen)

Däremot fungerar kombinationer med rumsadverbial såsom $p a ̊$ vinden/på taket: han gick upp/uppe på vinden/taket. Riktning kan 
i svenskan även markeras utan att verbet är ett rörelseverb som i satserna (I.I6) och (I.I7):

(I.I6) Dit ska du (gå)!

(I.I7) Vart ska du (gå)?

I dessa satser fungerar inte befintlighetsuttryck. ${ }^{3}$ Rörelseverben gå och åka eller rörelse i form av en resa, till exempel med tåg, bil eller flyg, är underförstått i kontexten. Beträffande vart i kombination med rörelseverb används uttrycket i frågor.

\section{Befintlighets- och riktningsuttryck i nederländska}

De nederländska befintlighetsuttrycken hier, daar, waar, binnen, buiten, thuis, boven, beneden motsvarar svenskans här, där, var, inne, ute, hemma, uppe, nere. För att uttrycka riktning används generellt en kombination av befintlighetsuttryck, riktningsprepositioner och adverb, se (I.I8), (I.I9) och (I.20)4.

(I.I8) Naar binnen/buiten/thuis 'in/ut/hem' (till inne/ute/hemma)

(I.I9) hier/daar/waarnaartoe 'hit/dit/vart'

(I.20) hier/daar/waarheen 'hit/dit/vart'

\section{Hier, daar och waar}

Befintlighetsuttrycken hier, daar och waar kan givetvis kombineras med statiska verb såsom zijn 'vara', staan 'stå', zitten 'sitta' och då uttrycker hela satsen en statisk befintlighet. Det intressanta är hur befintlighetsuttrycken fungerar för att markera rörelse på en och samma plats som i (I.2I) respektive rörelse mot ett mål som i (I.22).

(I.2I) We lopen hier in het nationale park.

'Vi går (till fots) här i nationalparken'.

(I.22) U loopt hier gemakkelijk naartoe.

'Ni går (till fots) hit utan problem'.

För adverbet daar gäller samma sak, se (I.23) och (I.24).

(I.23) Je wandelt daar in de voetsporen van vele schrijvers.

'Man vandrar där i många författares fotspår' 
(I.24) Het gezelschap wandelt daarnaartoe.

'Sällskapet vandrar dit'

I (I.2I) och (I.23) kombineras befintlighetsuttrycken med prepostionen in 'i' vilken även den anger befintlighet. I (I.22) och (I.24) anger naartoe att det handlar om riktning. I nederländskan används främst kombinationen waar+naartoe/heen tillsammans med rörelseverb i en fråga, jfr. (I.25) och (I.26).5

\section{(I.25) Waar loop je heen? 'Vart går du?' \\ (I.26) Waar gaat hij naartoe? \\ 'Vart ska han någonstans?'}

Det är även möjligt att fråga waar loop je nu? 'var går du nu' i betydelsen rörelse på en och samma plats. Verben komen 'komma' och brengen 'ta med sig, skjutsa' har förmågan att uttrycka riktning tillsammans med ett befintlighetsuttryck och i kombination med dessa verb behövs inte riktningsprepositionen naar 'till', jfr. (I.27) och (I.28).

(I.27) Ik kom hier al jaren.

'Jag har kommit hit i åratal'

(I.28) Hij brengt je daar.

'Han skjutsar dig dit'

Båda satserna i (I.27) och (I.28) innehåller alltså befintlighetsuttryck men uttrycker ändå riktning. ${ }^{6}$ Verben kan även kombineras med motsvarande riktningsuttryck hier/daarnaartoe och i princip uttrycka samma sak. Anledningen till detta är att verben i sig redan uttrycker riktning mot ett mål och oavsett om komen och brengen kombineras med befintlighetsuttryck får verbets semantik starkast genomslag i kombinationen. I (I.27) anger tidsadverbialet al jaren 'i åratal' att satsen är iterativ, vilket i någon mån uttrycker befintlighet på plats. Trots detta blir det tydligt av översättningarna att svenskan måste ha riktningsuttrycken hit respektive dit i dessa satser.

\section{Binnen-buiten, thuis-weg, boven-beneden}

I det följande behandlas motsatsparen binnen-buiten 'inne-ute', thuis-weg 'hemma-borta' och boven-beneden 'uppe-nere'. 
I Algemene Nederlandse Spraakkunst (ANS) behandlas bl.a. ovan nämnda rumsliga uttryck som adverb+verb och hur dessa formar sammansättningar (I997:609-63I). Dessa uttryck formar det som ANS kallar löst sammansatta verb där sammansättningen består av rörelseverb och befintlighetsuttrycken binnen, buiten, thuis, weg, boven och beneden.7 I vissa kombinationer med verb och befintlighetsuttryck kan riktning uttryckas, till exempel binnenkomen 'komma in'. Oftast finns även möjligheten att använda riktningsprepositonen naar + befintlighetsuttrycket för att förmedla samma riktningsbetydelse, till exempel naar binnen komen 'komma in'. Hur dessa kombinationer kan se ut tas upp nedan.

Binnen-buiten: i svenskan finns motsatsparen inne-ute och in-ut som är morfologiskt markerade för befintlighet respektive riktning. Nederländskans motsatspar binnen-buiten täcker delvis samma betydelsedomän som svenskans inne-ute. ${ }^{8}$ De nederländska befintlighetsuttrycken i kombination med vissa verb täcker även betydelsen riktning vilket motsvarar svenskans in-ut. I nederländskan är det främst befintlighetsuttrycket binnen 'inne' som kan kombineras med i princip alla rörelseverb, till exempel binnengaan, binnenbrengen, binnenkomen, binnenlopen, binnenrijden, binnenstappen, binnenvaren med riktningsbetydelse. Sammansättningen är således produktiv (se ANS I997:6 I3 och Van Dale Groot woordenboek der Nederlandse taal ${ }^{9}$ ).

(I.29) Je kunt de stad overal binnenrijden.

'Man kan köra in i stan överallt'

Vanligtvis kan konstruktionen i (I.29) omskrivas med naar binnen som i (I.30a) men inte om objektet de stad 'staden' till vilken rörelsen sker anges som i (I.3Ob).

(I.30a) Je kunt naar binnen rijden. 'Man kan köra in'

( $\mathrm{r} .3 \mathrm{Ob})$ * Je kunt de stad overal naar binnenrijden.

Detta gäller även för exempelvis binnenstappen 'gå på/kliva på'. Saknas ett objekt fungerar naar binnenstappen och om ett utsatt objekt finns i satsen fungerar endast binnenstappen. Jfr. (I.3 Ia) och (I.3 Ib). 
(I.3 Ia) Hij mag nu naar binnen stappen. 'Han får gå på nu'

(I.3 Ib) Hij mag nu de trein binnenstappen. 'Han får gå på tåget nu'

Även följande satser ger vid handen att rörelseverb inte behöver kombineras med till exempel riktningsprepositionen naar. Befintlighetsadverbet är tillräckligt för att betydelsen riktning ska skapas genom verbets semantik eller övrig kontext, se (I.32) och (I.33).

(I.32) Je loopt door de voordeur het huis binnen. 'Man går in i huset genom ytterdörren'

(I.33) Auto rijdt restaurant binnen. 'Bil kör in i restaurang'

I dessa satser placeras binnen sist och får funktionen postposition vilket också markerar riktning i nederländska.

För buiten ser kombinationsmöjligheterna lite annorlunda ut med fler restriktioner än för binnen vad gäller rörelseverb som tillsammans med adverben betecknar riktning. Verb med buiten tas också upp i Van Dale Groot woordenboek der Nederlandse taal men där betecknas dessa framför allt som belgisk nederländska $^{\mathrm{IO}}$ : buitenvaren, buitenrijden, buitenkruipen och så vidare. Sammansättningar med buiten och verben gaan, lopen, brengen tas överhuvudtaget inte upp. I ANS (I997:6I4) beskrivs buiten som icke produktiv och endast ett begränsat antal sammansättningar nämns: buitenkomen 'komma ut', buitensluiten 'stänga ut', buitenstrompelen 'snubbla ut', buitenwerpen 'kasta ut', buitenzetten 'sätta ut'. För att uttrycka gå ut kan man både använda uitlopen/uitgaan eller naar buiten lopen/naar buiten gaan, jfr. (I.34) och (I.35).

(I.34) Je loopt door de voordeur het huis nit. 'Man går ut ur huset genom ytterdörren'

(I.35) Ze gaan naar buiten.

'De går ut'

I (I.34) fungerar uit som postposition och anger därmed automatiskt riktning. I princip är just kombinationen naar buiten + rörelseverb den mest frekventa för att uttrycka en rörelse från en plats 'inne' till en plats 'ute'. 
Thuis-weg: i svenskan finns motsatsparen hemma-borta och hem-bort som är morfologiskt markerade för befintlighet respektive riktning. Vad gäller weg finns inte möjligheten att bilda kombinationen naar weg, enligt mönstret ovan med riktningsprepositionen naar 'till'. Weg i betydelsen 'inte längre vara på en viss plats' kombineras både med rörelseverb och statiska verb och uttrycker då, i kombination med verbet, befintlighet som i (I.36) och riktning som i ( 1.37$)$.

(I.36) Niemand is thuis, iedereen is weg. 'Ingen är hemma, alla är borta'

(I.37) Wij reizen morgen weg. 'Vi reser bort imorgon'

I (I.36) innehåller satsen det statiska verbet zijn och i (I.37) är reizen ett rörelseverb. Weg översätts ofta med svenskans iväg som exempelvis i ( $\mathrm{I} .38$ ).

\section{(I.38) Zij rent weg.} 'Hon springer iväg'

Sammansättning med weg är produktiv och i princip kan adverbet kombineras med alla rörelseverb, till exempel weglopen,wegkomen, wegrijden med flera, och uttrycker riktning (ANS 1997:630).

Thuis 'hemma' anger befintlighet och för att uttrycka riktning används vanligen kombinationen naar huis 'hem', jfr. (I.39) och (I.40).

(I.39) De vader is thuis.

'Pappan är hemma'

(I.40) Ik loop naar huis.

'Jag går hem'

I (I.39) är verbet statiskt vilket innebär att endast befintlighetsuttrycket thuis är möjligt och i (I.40) uttrycker verbet rörelse och riktningsuttrycket naar huis används. Van Dale Groot woordenboek der Nederlandse taal och ANS (I997:627) anger dock ett mindre antal rörelseverb där kombinationen med befintlighetsuttrycket thuis anger riktning och inte befintlighet, till exempel thuisbrengen 'skjutsa hem', thuissturen 'skicka hem', thuishalen 'hämta hem' och thuiskomen 'komma hem'. ANS anger också att thuis inte är produktivt men ovanstående kombinationer är alltså möjliga, dock i princip begränsade till dessa. Brengen, sturen, 
halen och komen har betydelsen riktning inherent och då är inte riktningsprepositionen naar överhuvudtaget nödvändig. Det löst sammansatta verbet thuislopen har en överförd betydelse 'vara arbetslös' och motsvarar därmed svenskans 'gå hemma' vilket uttrycker befintlighet på en och samma plats. För övriga kombinationer med rörelseverb utan inherent riktningsbetydelse måste naar huis användas och kombination med endast befintlighetsuttryck är ogrammatiskt, se (I.4I) och (I.42).

\section{(I.4 I) Hij gaat naar huis. 'Han går hem' \\ (I.42) *Ze gaan thuis. 'De går hemma'}

Boven-beneden: i svenskan finns motsatsparen uppe-nere och upp-ner som är morfologiskt markerade för befintlighet respektive riktning. Nederländskans motsvarande ordpar är bovenbeneden. Boven är inte produktivt i sammansättningar med verb, enligt ANS (I997:6I4). Dock nämns kombinationen bovenkomen 'komma upp', bovenkrijgen 'få upp' och bovendrijven 'flyta upp' där riktning kan uttryckas med ett rörelseverb och befintlighetsuttryck. I övriga kombinationer med verb krävs alltså konstruktioner med riktningsprepositionen naar för att uttrycka riktning, till exempel i (I.43).

\section{(I.43) Ik ga naar boven.} 'Jag går/åker upp'

Beneden betraktas överhuvudtaget inte som ett adverb som bildar en sammansättning med ett verb. ${ }^{\text {II }}$ För beneden gäller alltså att uttrycket uteslutande kombineras med riktningsprepositionen naar och ett rörelseverb där hela kombinationen uttrycker riktning, se (I.44).

\section{(I.44) Het kind springt naar beneden. 'Barnet hoppar ner'}

Op och af fungerar också som riktningsuttryck för upp och ner men fungerar då som postpositioner och kategoriseras därför inte som sammansättningen adverb+verb: hij loopt de trap af 'han går nerför trappan' och zij gaat de trap op 'hon går uppför trappan'. 


\section{Verbet komen}

Kärnverbet komen 'komma' intar en särställning då verbet kan kombineras med både befintlighetsuttryck och uttryck med riktningsprepositionen naar 'till', hier /daarnaartoe 'hit/dit' eller hier/ daarheen 'hit/dit'. Det speciella är att komen tillsammans med både befintlighets- och riktningsuttryck endast uttrycker riktning, se Tabell I.I.

Tabell 1.1. Rumsliga uttryck i kombination med komen.

\begin{tabular}{ll}
\hline Befintlighetsuttryck & Riktningsuttryck \\
\hline thuiskomen & naar huis komen \\
wegkomen & - \\
binnenkomen & naar binnen komen \\
buitenkomen & naar buiten komen \\
bovenkomen & naar boven komen \\
- & naar beneden komen \\
hier komen & hiernaartoe/hierheen komen \\
daar komen & daarnaartoe/daarheen komen \\
\hline
\end{tabular}

Anledningen till att dessa rumsliga uttryck i kombination med komen endast uttrycker riktning beror på verbets semantiska målbetydelse (Johansson 2006). ${ }^{\mathrm{I} 2}$ Dock finns betydelsenyanser att ta hänsyn till vid användandet av komen i kombination med uttrycken i Tabell I.I, jfr. (I.45) och (I.46).

(I.45) Ik kom over een uur thuis.

'Jag är hemma om en timme/jag kommer hem om en timme'

(I.46) Ik kom over een uur naar huis.

'Jag åker hem om en timme'

Här ser man att thuiskomen egentligen betyder att utgångspunkten är hemma, dvs. fokus ligger vid målet medan naar huis komen har fokus vid utgångspunkten, rörelsen mot målet inleds. Följande exempelmeningar anger också en betydelsenyans:

( .47) Dinsdagochtend, je komt binnen op kantoor en gaat direct aan de slag. 
'Tisdagmorgon, man kommer in på kontoret och börjar jobba direkt'

(I.48) Kleuters komen naar binnen door de zijdeur.

'Dagisbarnen kommer in genom sidodörren'

Det är ingen skillnad i översättning men binnenkomen i ( I.47) anger att subjektet kommer till jobbet och är där (målfokus) medan naar binnen komen i (I.48) uttrycker att själva rörelsen accentueras, hur dagisbarnen kommer in och att det sker via en dörr.

Hier komen respektive hiernaartoe komen uppvisar en liknande betydelsenyans, jfr. (I.49) och (I.5O):

(I.49) De pers komt hier alleen als er ellende is. 'Pressen är här/kommer bara hit när något elände hänt'

(I.5O) Ik kom hiernaartoe omdat ik thuis niets te doen heb. 'Jag kommer hit för att jag inte har något att göra hemma'

Betydelsen hos hier komen i (I.49) har målfokus där det rumsliga uttrycket anger att pressen är på plats medan satsen med hiernaartoe komen i (I.50) fokuserar på processen, dvs. själva förflyttningen. Här förflyttar sig subjektet från hemmet 'thuis' till en annan plats och det är på den processen som fokus ligger.

Om man vill uttrycka att man regelbundet kommer till en viss plats kan befintlighetsuttrycken hier och daar användas:

(I.5 I) We komen hier/daar redelijk vaak.

'Vi kommer hit/dit ganska ofta'

Satsen i (I.5I) anger ett slags repetitiv rörelse dvs. iterativ betydelse. Denna betydelse skapas således när komen kombineras med hier eller daar. I ( I.49) kan satsens betydelse också beskrivas som iterativ: varje gång pressen kommer hit (...). Hier/daarnaartoe i kombination med komen fokuserar på själva förflyttningen som en process.

\section{Sammanfattning}

Svenskans morfologiska markering för befintlighet och rörelse i kombination med rörelseverb utgör ett relativt regelbundet system där det rumsliga adverbets markering avgör huruvida satsen 
uttrycker riktning eller befintlighet. Nederländskans möjlighet att uttrycka befintlighet respektive riktning går inte att koppla till adverbet då det saknar morfologisk markering motsvarande svenskans system. Här spelar verbens betydelse och kontexten en stor roll samt att nederländskan använder postpositioner för att uttrycka riktning. Vissa verb kombinerade med befintlighetsuttryck förefaller dessutom lexikaliserade, speciellt vad gäller kärnverbet komen.

\section{Noter}

I. Det som har utsträckning i rummet och som kan observeras räknas som konkret, till exempel människor, djur och saker. Det som inte har utsträckning i rummet räknas som abstrakta fenomen såsom beslut, känsla och begrepp (se till exempel Vogel 20II:53).

2. I Deskriptiv svensk grammatik (I993:I30-I3I) beskrivs också denna distinktion mellan befintlighet och riktning vad gäller rumsliga adverb.

3. I talad svenska är det dock vanligt att var och vart används utan att distinktionen mellan befintlighet och riktning görs.

4. Beroende på kontext kan hier/daarnaartoe och hierheen/daarheen även översättas med hitåt och ditåt. Waarnaartoe skulle kunna översättas med vartåt och waarheen kan översättas med varthän.

5. Naartoe och heen skiljer sig åt rent stilistiskt i det att heen är mer formellt.

6. Svenskans komma kan i vardagligt tal kombineras med befintlighetsuttrycket här i satser som kom inte här och klaga. Det är emellertid inte främst riktning som uttrycks i dessa kontexter till skillnad från nederländskans komen + hier som har riktningsbetydelse.

7. I svensk språkvetenskap benämns löst sammansatta verb ofta partikelverb eller som i SAG verb med partikeladverbial. Dock bildar inte alla partikeladverbial lösa sammansättningar.

8. in och uit fungerar delvis parallellt med binnen och buiten.

9. Van Dale Groot woordenboek der Nederlandse taal är den ordbok

i 3 delar som ges ut av Van Dale Lexicografie. 
ı०. Varietet som talas i Flandern, den norra delen av Belgien.

I I. Beneden tas inte upp under kapitlet om bijwoord + werkwoord i ANS utan benämns voorzetsel 'preposition' och 'voorzetselbijwoord 'prepositionsadverb' (se till exempel ANS I997:46I).

I2. Till exempel brengen 'föra med sig, skjutsa' har samma semantiska målbetydelse och kan också skapa riktningsbetydelse med ett befintlighetsuttryck: ze brengen me thuis 'de skjutsar hem mig'. 